\title{
Anti-EGFR Therapy: Strategies in Head and Neck Squamous Cell Carcinoma
}

\author{
Renato J. Oliveira-Silva ${ }^{1}$, Ana-Carolina de Carvalho ${ }^{1}$, Luciano de Souza Viana ${ }^{1,2}$, \\ André L. Carvalho ${ }^{1, *}$ and Rui M. Reis ${ }^{1,3,4, *}$
}

${ }^{1}$ Molecular Oncology Research Center, ${ }^{2}$ Department of Medical Oncology, Barretos Cancer Hospital,
Barretos, São Paulo, Brazil; ${ }^{3}$ Life and Health Sciences Research Institute (ICVS), Health Sciences
School, University of Minho, Braga, Portugal; ${ }^{4}$ ICVS/3B's-PT Government Associate Laboratory,
Braga/Guimarães, Portugal

Received: November 19, 2015; Accepted: March 6, 2016; Revised: March 6, 2016

\begin{abstract}
Epidermal growth factor receptor (EGFR) is a tyrosine kinase receptor that activates downstream signaling pathways, including the Ras-MEK-Erk and PI3K-AKT pathways, leading to cell proliferation, resistance to apoptosis, angiogenesis and the ability to metastasize. EGFR overexpression is a significant finding in cancer, particularly in head and neck cancer, where it is also associated with a poor prognosis. In recent years, several molecules have been designed to inhibit EGFR activation. Among the many available anti-EGFR drugs, only cetuximab was approved for the treatment of head and neck cancers. However, no predictive biomarkers of cetuximab response are currently known. In the present review, we provide an updated assessment of EGFR biology and its clinical impact in head and neck cancers. A special emphasis is placed on novel patents of EGFR-inhibitors that are anticipated to diversify the anti-EGFR therapies available to treat head and neck cancers. In particular, we outline a new class of irreversible multi-target inhibitors (e.g. afatinib, icotinib, CUDC-101), which may significantly contribute to new head and neck cancer therapies.
\end{abstract}

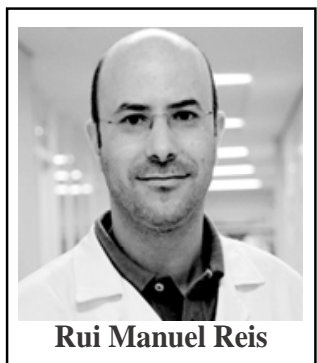

Keywords: Anti-EGFR patents, EGFR, EGFR overexpression, head and neck squamous cell carcinoma, tyrosine kinase inhibtors, targeted therapies.

\section{INTRODUCTION}

Head and neck cancer is the sixth most common cancer worldwide with a global incidence between 400,000 and 600,000 new cases per year and a mortality rate of 300,000 deaths annually [1-3]. It comprises a spectrum of malignancies that, develop primarily within the oral cavity, pharynx, and larynx. Squamous cell carcinoma is the principal histologic subtype of this disease, accounting for more than $90 \%$ of all cases $[4,5]$. The high incidence and mortality rate make these cancers a significant public health problem [6]. Head and neck squamous cell carcinoma (HNSCC) patients have a $50 \%$ five year survival rate, which is highly dependent on the stage at diagnosis [7]. Accurate assessment of clinical symptoms, physical examination and laboratory results are of paramount importance to guide diagnostic approaches, staging and choice of therapy [8].

The treatment plan depends upon patient and diseaserelated factors, such as the site of the primary tumor, the stage of the disease (early-stage $v s$. advanced-stage), feasibility of organ preservation, the ECOG performance status

\footnotetext{
*Address correspondence to these author at the Barretos Cancer Hospital, Rua Antenor Duarte Villela, 1331, CEP 14784 400, Barretos, S. Paulo, Brazil; Tel/Fax: +551733216600 - Extension: 7090;

E-mail: ruireis.hcb@gmail.com

Barretos Cancer Hospital, Rua Antenor Duarte Villela, 1331, CEP 14784 400, Barretos, S. Paulo, Brazil; Tel:/Fax: +551733216600 - Extension: 7092; E-mail: carvalhoal@gmail.com
}

(Eastern Cooperative Oncology Group), significant comorbidities and the goal of therapy [8]. Patients harboring early stage disease (stage I and II) are potentially curable with single modality treatments (either surgery or radiation). Advanced disease patients (stage III and IV) require a multidisciplinary and multimodality approach with a combination of surgery, radio- and chemotherapy [8]. Despite recent advances in radio- and chemotherapy, survival rates of HNSCC patients remain poor. Local recurrences are frequent and 20$30 \%$ of cases will develop metastatic disease [9].

Extensive surgeries involving the resection of the primary tumor and cervical lymph nodes usually cause functional and aesthetic consequences, having a great impact on a patient's quality of life [8]. The standard treatment for most patients is currently multimodal, and includes combined chemotherapy and radiotherapy. Moreover, the addition of induction chemotherapy (IC) remains an appropriate approach for advanced disease with a high risk of local or distant failure [8]. Platinum and taxane combinations are the backbone of several IC regimens for locally advanced head and neck cancers (LAHNSCC) and the TPF (docetaxel, cisplatin and fluorouracil) regimen is the most accepted induction regimen for LAHNSCC [10].

Tobacco and alcohol use are the most common risk factors for HNSCC and the human papillomavirus (HPV) has been recently established as a cause of oropharyngeal cancer $[11,12]$. Tobacco use is the main risk factor for HNSCC 
carcinogenesis, with smokers having a 5 to 25 fold risk compared to non-smokers [13], due to the genotoxic effects of carcinogenic substances in tobacco [14]. Alcohol consumption is relevant for HNSCC development for its capacity to synergistically enhance the carcinogenic effects of tobacco [15]. Moreover, the acetaldehyde metabolite forms DNA adducts that interfere with synthesis and repair [16].

HPV is found in $23-35 \%$ of all HNSCC biopsies [17] and in $45-90 \%$ of oropharyngeal cancers [17-20]. HPV-16 is the most prevalent subtype, occurring in $87-90 \%$ of HPVpositive oropharyngeal cancers [21-23]. A recent comprehensive integrative genomic analysis of HNSCC and HPV status was performed by mapping RNA-Seq reads of 279 patients and it was observed that $12 \%(36 / 279)$ were HPV(+). Of 33 oropharyngeal tumours, 64\% (21/33) were positive for HPV. The HPV(+) subset of oropharyngeal HNSCCs, exhibited a loss of TRAF3 (TNF ReceptorAssociated Factor 3), activating mutation of PIK3CA, and amplification of E2F1 (E2F Transcription Factor 1) involving NF-kB, activation. In $\mathrm{HPV}(+) \mathrm{HNSCCs}$, the most prominent findings were subsets containing amplicons on $11 \mathrm{q}$ with CCND1, FADD, BIRC2 and YAP1 and mutually exclusive CASP8 and HRAS mutations. Importantly, these findings in HPV-associated cases may have the potential to be used as tools for treatment decisions [24].

Recently, molecular alterations underlying HNSCC tumorigenesis have been explored [24-29]. One of the pivotal molecules is the EGFR, which is overexpressed in more than $90 \%$ of HNSCCs $[30,31]$. EGFR is upregulated not only in HNSCC but also in the vast majority of solid tumors, becoming, therefore, a major target for molecular therapies [32, 33].

Based on EGFR expression in HNSCC, cetuximab, a chimeric monoclonal antibody that binds with high affinity to the EGFR, has been used in the United States since 2006 as first-line treatment in combination with radiation therapy for LAHNSCC [34] or as a single agent for patients with metastatic disease and poor responses to platinum-based regimens [35]. In 2011, combinations of cetuximab with other agents were approved by the U.S. Food and Drug Administration for the first line of treatment of HNSCC. Cetuximab combination therapy with cisplatin or carboplatin and 5-fluorouracil was based on a multi-center clinical study involving 442 participants that, demonstrated an improvement in survival [36].

In the present review, we will perform an updated assessment of EGFR biology in HNSCC and its clinical impact, with a special emphasis on novel, multi-target EGFRinhibitors, which may transform HNSCC therapy.

\section{EPIDERMAL GROWTH FACTOR RECEPTOR (EGFR)}

The EGFR was discovered in the 1970s. Cohen and colleagues isolated a protein that caused precocious tooth eruption in neonatal mice, now known as EGF (epidermal growth factor) [37]. A few years later, the same research group identified a high level of radio-labeled EGF bound to the cytoplasmic membrane of A431 squamous carcinoma cell lines. This was the first evidence of a membrane receptor with affinity to EGF, the EGFR [38].
EGFR belongs to the ErbB receptor family (EGFR, ErbB2/Neu/Her2, ErbB3/Her3 and ErbB4/Her4), and the protein is composed of 1210 amino acids with four extracellular domains (ED), a transmembrane domain (TD) and an intracellular tyrosine kinase domain (TKD) (Fig. 1). Its carboxylterminal tail contains several phosphorylation sites: one serine residue (Ser-1142), one threonine residue (Thr-654) and seven tyrosine residues (Try-845, 992, 1045, 1068, 1086, 1148, 1173) [39, 40]. EGFR can be activated by several specific ligands: (1) Amphiregulin, (2) Betacellulin, (3) Epiregulin, (4) Neuregulin, (5) Heparin-binding EGF, (6) Transforming growth factor alpha (TGF- $\alpha$ ) and (7) EGF (Fig. 1). Under normal physiological conditions, all four ErbB receptors can form 10 possible dimer combinations including 4 homodimers and 6 heterodimers. Each combination has specific affinity for signaling in effective intracellular pathways [40, 41] (Fig. 1).

EGFR ligands cause a conformational change, resulting in domain II interaction and receptor dimerization (Fig. 1) [39]. In addition, EGFR phosphorylation sites can activate downstream protein kinases such as the Src kinase family, protein kinase $\mathrm{C}$ and protein kinase A. EGFR itself is also able to phosphorylate other protein residues and target downstream signaling such as the MAPK, STAT and PI3K/AKT pathways, which control cell survival, proliferation, migration, differentiation, and adhesion [42-45].

\subsection{EGFR Deregulation in Tumors}

Due to its significance in the regulation of multiple cellular mechanisms, EGFR homeostasis is key to normal function. Inasmuch, EGFR activity and regulation is tightly controlled by a plethora of mechanisms including copy number variation, single nucleotide polymorphism (SNP), alternative splicing, phosphorylation, ligand availability, dimerization partner availability, trafficking and degradation [46]. In the pathogenesis of cancer, EGF/EGFR is deregulated at several levels, namely: autocrine/paracrine factors; gene amplification; gene mutations, and protein nuclear translocation. All of these alterations lead to overexpression or constitutive activation of related signaling pathways (Fig. 1).

\subsubsection{Autocrine/Paracrine Factors}

EGFR-mediated neoplastic transformation may be effected by autocrine/paracrine mechanisms of overexpression of both EGFR and its ligands, providing multiple advantages to tumors through the promotion of cell proliferation, survival, angiogenesis, invasion and metastasis. Most studies that have analyzed EGFR protein in HNSCC patients, used immunohistochemistry (IHC) methodologies on paraffinembedded tumor samples, and described EGFR overexpression in 43 to $100 \%$ of cases (Table 1). These discrepancies between EGFR overexpression rates might be the result of the type of antibodies or fixative used, differences in IHC technique, and storage time of samples. Nevertheless, the biological role of EGFR overexpression in HNSCC is unquestionably significant. Interestingly, a recent meta-analysis evaluated EGFR expression as a prognostic factor in HNSCC [47]. This meta-analysis included 37 studies and found that overall, EGFR overexpression was associated with reduced overall survival (OS) hazard ratio (HR) of 1.694, $95 \%$ confidence interval (CI): 1.432-2.004) [47]. 


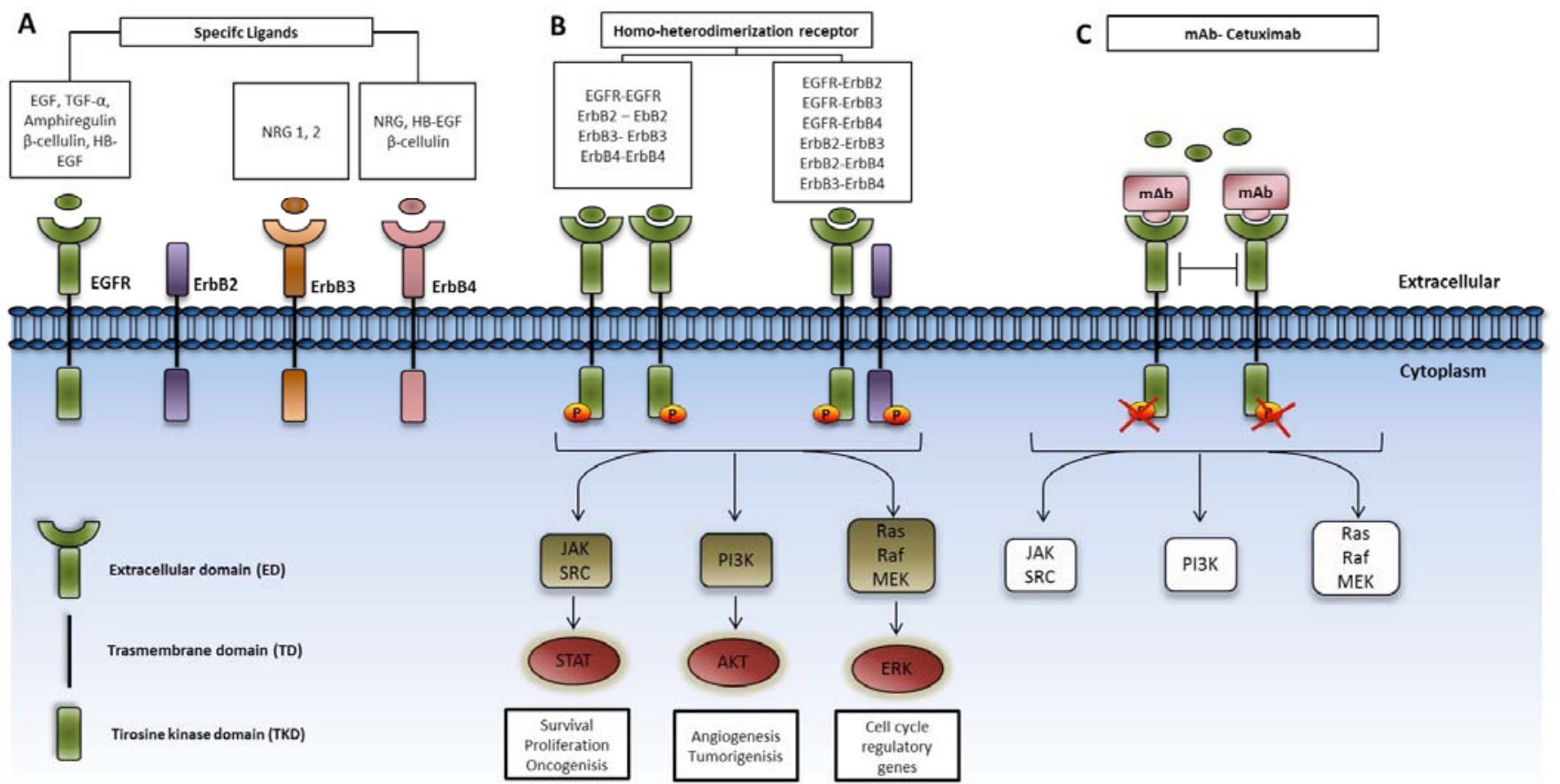

Fig. (1). A- ErbB family receptor: EGFR/HER1, ErbB2/Neu/Her2, ErbB3/Her3 and ErbB4/Her4. All ErbB family receptors, except ErbB2 bind to specific ligands allowingthe improvement of receptor dimerization. B- Multiple combinations of homodimers receptor (4) and heterodimers receptor (6). Receptor phosphorylation promotes the activation of intracellular pathways that control proliferation, angiogenesis and metastasis. C- Cetuximab action, the only chemotherapeutic agent against EGFR, approved for use in HNSCC patients. The monoclonal antibody competes with the ligand and blocks dimerization and phosphorylation receptor.

A majority of carcinomas express EGF-like growth factors that, contribute to increased signaling mediated by EGFR activation [45, 48]. A decade ago, the co-expression of EGFR and its ligands in the tumor microenvironment was hypothesized to have an important role in carcinogenesis and progression in patients with HNSCC [49]. Recently, The Cancer Genome Atlas (TCGA) offered a comprehensive and extensive landscape of somatic genomic alterations in HNSCC patients, including mRNA expression levels of the ErbB family ligands (supplementary Table 1). In total, HRG, NRG4 and NGR1 mRNA levels, were upregulated in 15, 7 and $6 \%$ of cases, respectively, while EGF, AREG and EREG mRNA levels were upregulated in $4 \%$ of cases [24].

The TNF gene family, although it typically has low mRNA expression levels (2\%) [24], is implicated with autocrine neoplastic transformation and increased proliferation in HNSCC cell lines [50]. In the clinical setting, patients with upregulated TNF mRNA expression had an overall survival estimate of 12.98 months compared to patients with normal TNF expression (21.85 months) (supplementary Table 1). Amphiregulin (AREG) overexpression is associated with an increased risk of developing breast cancer [51], lung, colorectal, ovary and prostate carcinomas [52]. AREG overexpression was detected in 4\% (12/279) of HNSCC patients and associated with a mean overall survival of 28.29 months compared to 21.75 months for patients with normal expression (supplementary Table 1). Heparin binding-EGF (HBEGF) is an EGF mainly produced by monocytes and macrophages. Some studies have associated HB-EGF expression with the development of malignant phenotypes including a metastatic mechanism that displays aggressive tumor behav- ior $[53,54]$. HB-EGFR is upregulated in human breast carcinomas, ovarian, gastric, melanoma and glioblastoma tumor cell lines [55-57]. In HNSCC, HB-EGF expression is altered in $4 \%(11 / 279)$ of cases (supplementary Table 1). Heregulin (HRG) is the most expressed ligand in HNSCC patients and present in 15\% (46/279) of cases (supplementary Table 1). Interestingly, patients with HRG mRNA upregulation have a higher mean overall survival (42.32 months) compared to patients with normal expression levels (21.85 months) (supplementary Table 1).

\subsubsection{EGFR Amplification}

Gene amplification of the EGFR has been observed in distinct tumors, including gliomas, colorectal, esophageal, breast and pancreatic cancers [58-64]. Several studies have detected increased EGFR copy number in HNSCC patients ranging from 7.8 to $58 \%$ (Table 1). The most comprehensive study was performed by the TCGA and reported a frequency of $11 \%$ of EGFR gene amplification, which induced EGFR overexpression, therefore demonstrating its pathogenic effect [24]. In addition, the authors showed EGFR gene amplification was associated with worse patient outcomes, with overall survival of 17.15 months in EGFR amplified cases versus 26.41 months in patients without gene amplification [24].

\subsubsection{EGFR Mutation}

The majority of the EGFR somatic mutations identified in tumors are concentrated in the extracellular and intracellular tyrosine kinase domains, clustered in specific areas, which assumes the role of mutational hot spots. Initial studies in lung cancer showed the importance of mutations involving exons 18, 19, 20 and 21, which encode a portion of 
Table 1. Review of EGFR Molecular Alterations in HNSCC.

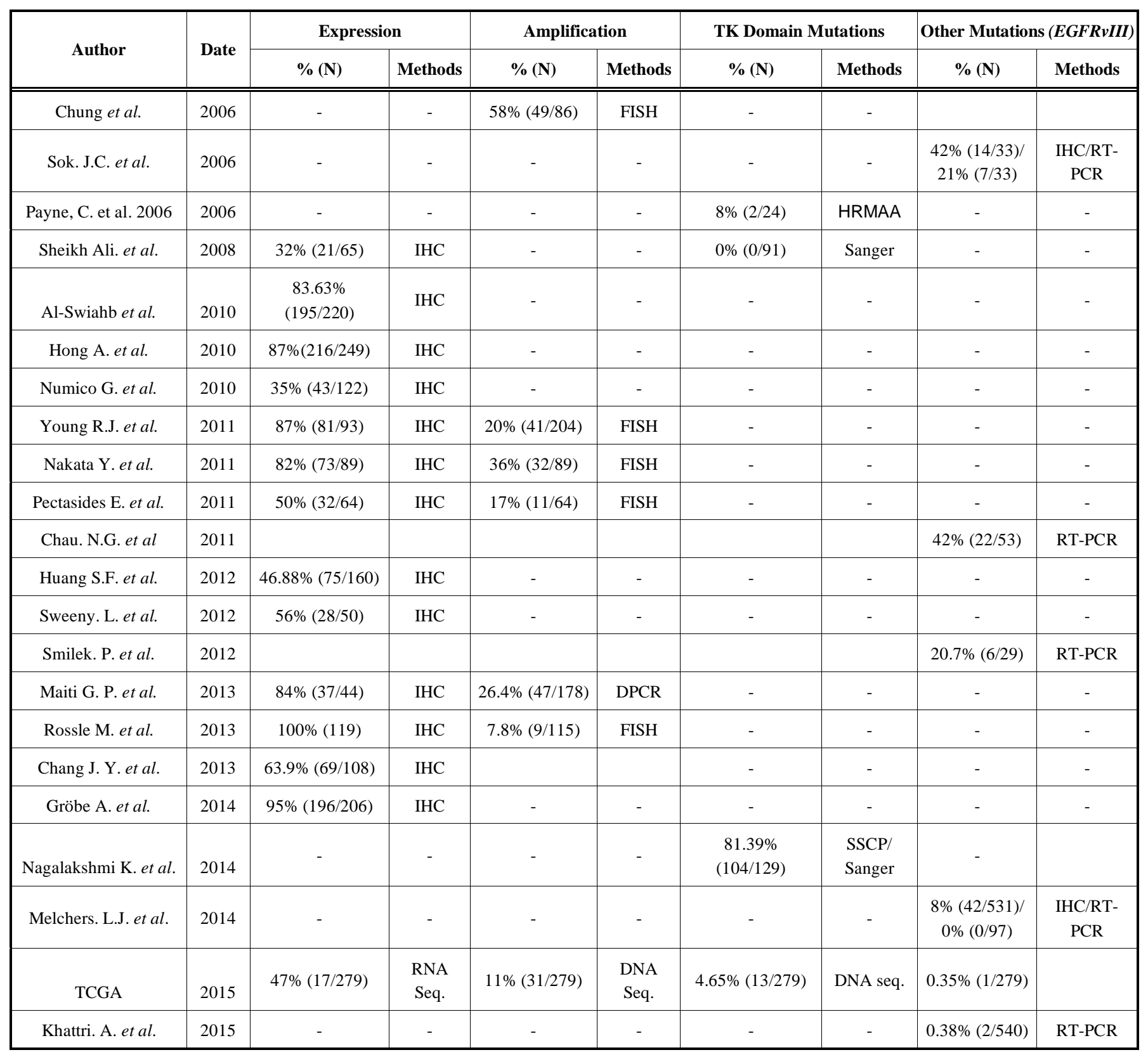

IHC: Immunohistochemistry; FISH: Fluorescence in situ hybridization; DPCR: differential polymerase chain reaction; RT-PCR: Reverse transcription polymerase chain reaction; HRMAA: High-resolution melting amplicon analysis; SSCP: single-strand chain polymorphis; RNA Seq: RNA Sequencing.

the EGFR tyrosine kinases domains [65]. These mutations predict patient responses to anti-EGFR drugs, such as erlotinib and gefitinib, and are assessed on a routine basis [65].

In HNSCC, the data available is more limited. Despite a disparity of published research, a low frequency of EGFR somatic mutations has also been reported in these tumors (Table 1). Nagalakshmi et al, using SSCP followed by sequencing, observed a mutation frequency of $81.4 \%$ in cases. In contrast, other studies and more recently, the TCGA consortium, showed that EGFR mutations are rare events, present in less than $10 \%$ of cases (Table 1, Supplementary Table 2) $[24,66,67]$. The lack of $E G F R$ somatic mutations in available HNSCC cell lines reinforce the absence of this event in HNSCC tumorigenic process [68].

One mutation in HNSCC that has gained particular attention is the EGFRvIII, which is located in the extracellular domain [69]. The EGFRvIII is described by an in-frame deletion of 267 amino acids in the extracellular domain, resulting in the loss of exons 2 to 7 . The instability in the extracellular domain of EGFRvIII results in significant functional changes in the EGFR and acquires constitutive tyrosine kinase activity [70]. This mutation was first detected in glioblastomas, and later studies reported its presence and importance in HNSCC (Table 1). The first studies used immunohistochemistry and reverse transcription-PCR, and 
Table 2. Anti-EGFR Agents and Multi-Target Action. Recent Clinical Trials for HNSCC

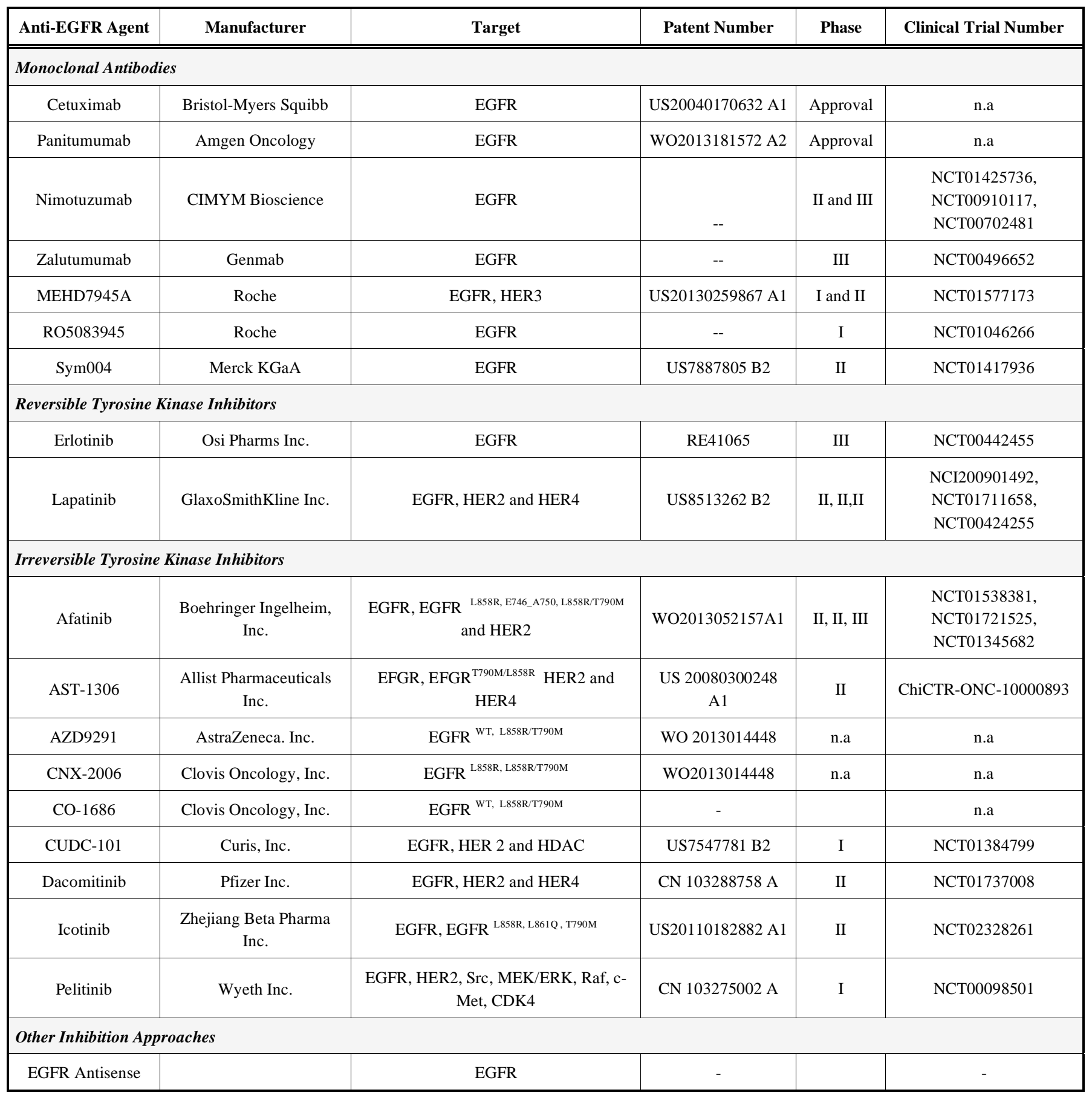

n.a: not available.

detected EGFRvIII in approximately $40 \%$ of cases. In vitro studies were also performed, suggesting a biological role in HNSCC tumorigenesis and (cetuximab) therapy response [71]. The presence of EGFRvIII in HNSCC was also reported by other authors in frequencies varying from $8-42 \%$ (Table 1). However, more recent studies (including the TCGA consortium) performed using more accurate methodologies do not confirm these findings and report an absence or very low frequency of EGFRvIII in HNSCC (Table 1) [72-74].

\subsubsection{Protein Nuclear Translocation}

The first discovery of nuclear translocation was observed in hepatocyte regeneration studies in the last decade [75]. Additionally, EGFR internalization and nuclear translocation has been demonstrated in different healthy tissue types such as the uterus of pregnant mice and mouse embryos [76]. The classic EGFR translocation mechanism occurs in proteins containing nuclear localization sequences (NLS) that interact with importin $\alpha / \beta$ protein, which mediates interactions with 
the nuclear pore complex (NPC) [77]. Subsequently, EGFR nuclear localization is correlated with increased cellular proliferation, supporting the role of EGFR as a transcription factor of cyclin D1 genes [78] that mediate synthesis of proliferating cell nuclear antigen (PCNA), which is a DNA polymerase delta cofactor [79]. Over the last decade, several studies have suggested that, nuclear expression of EGFR may be an important molecular determinant of resistance to cetuximab therapy [80]. Specifically, EGFR nuclear translocation was evaluated in a cetuximab-resistant cell line that demonstrated increased nuclear localization of EGFR, mediated by the Yes and Lyn proteins which belong to Src family kinase family [81]. Furthermore, a non-invasive methodology to monitor the response to EGFR-inhibitor treatment has been tested in mice with HNSCC xenografts using [64] $\mathrm{Cu}-$ cetuximab-F(ab')2, an EGFR-directed PET tracer [82] or (111) In-cetuximab-F( $\left(\mathrm{ab}^{\prime}\right)(2)$ [83]. An experimental approach observed that EGFR nuclear translocation is associated with DNA-PKcs in DNA repair after exposure to cisplatin or ionizing radiation (IR), and is required for the repair of DNA damage [84]. The role of EGFR traffic has been associated with HNSCC resistance to multimodal therapy. The use of radiolabeled EGFR-inhibitors may be an efficient tool to monitor clinical response [85].

\section{EGFR INHIBITORS}

Due to the central role of EGFR in several tumors, the scientific community and pharmaceutical companies designed agents that could specifically inhibit EGFR. Two major strategies were developed: monoclonal antibodies (mAbs) and small molecule tyrosine kinase inhibitors (TKIs).

\subsection{Monoclonal Antibodies}

Cetuximab (Erbitux ${ }^{\circledR}$, Bristol-Myers Squibb; New York, NY.) is a chimeric human-murine monoclonal antibody that binds competitively to EGFR. Cetuximab is $152 \mathrm{kDa}$, made up of four polypeptide chains: two heavy (lambda) chains (449 amino acids) and two light (kappa) chains (214 amino acids). Both chains contain one and two consensus sequences for N-linked glycosylation [86]. Cetuximab prevents stimulation by EGF and TNF- $\alpha$ endogenous ligands, disrupting intracellular signaling [87]. Blocking this receptor reduces proliferation, metastasis, angiogenesis and increases apoptosis levels [88]. In February 12, 2004, the Food and Drug Administration (FDA) approved cetuximab in combination with irinotecan, for the treatment of metastatic colorectal carcinoma in patients refractory to irinotecan-based chemotherapy [89]. In 2006, cetuximab was approved by the FDA [90] for the treatment of LAHNSCC and is so far the only anti-EGFR agent for its treatment in combination with radiation and chemotherapy, or as a monotherapy for recurrent, metastatic HNSCC that is unresponsive to platinum-based chemotherapy [36].

In the Phase III EXTREME trial, patients with recurrent or metastatic HNSCC were treated with a chemo/cetuximab combination had prolonged overall survival rates compared with patients treated with chemotherapy alone (median 10.1 versus 7.4 months, HR for death $0.80,95 \%$ CI 0.64 to 0.99 ) [91]. However, in Eastern Cooperative Oncology Group
Study phase III, patients with metastatic or recurrent HNSCC were randomized to cisplatin plus placebo or cisplatin plus cetuximab. Progression-free survival (PFS) and overall survival (OS) were not significantly improved [92].

Panitumimab (Vectibix ${ }^{\circledR}$, Amgen, Thousand Oaks, CA, USA) is anti-EGFR monoclonal antibody that has been evaluated as an adjuctive therapy to traditional chemotherapy (cisplatin and 5-fluorouracil) in HNSCC patients. However, a Phase III study (SPECTRUM trial) did not show and improvement in OS in patients with recurrent or metastatic HNSCC, but did show an improvement in PFS and had an acceptable toxicity profile [93]. Another study demonstrated that among patients with a positive HPV status, as assessed by p16 immunohisstochemistry, showed increased PFS after treatment with cisplatin and fluorouracil plus panitumumab. Therefore, the authors suggested that p16 status might be important considerations in future trials with HNSCC patients [93].

Currently, clinical trials are using the combination of panitumumab in combination with other chemotherapeutic agents. At present, the benefit of combined panitumumab and paclitaxel therapy as a first-line treatment is being conducted in HNSCC patients (NCT01264328).

Nimotuzumab (TheraCIM, CIMYM Bioscience, Ontario, Canada) is another type of humanized chimeric monoclonal antibody. It binds to different epitopes in domain III of the extracellular region of EGFR. Several Phase I, II and III trials have been conducted in patients with HNSCC (NCT01425736, NCT00910117 and NCT00702481). A recent phase II pharmacodynamic trial of nimotuzumab was conducted in 10 unresectable HNSCC patients and demonstrated positive results, and also there was no evidence of skin rashes during 8 weeks of treatment [94]. An advanced approach is being carried to evaluate the association of nimotuzumab in combination with DCF (docetaxel, cisplatin and 5-fluorouracil) in recurrent or metastatic HNSCC (NCT01425736) [95]. An ongoing Phase II trial (NCT00702481) intends to define the response and toxicities associated with the addition of nimotuzumab to chemoradiation based on cisplatin for LAHNSCC. Additionally, Nizotumubab plus radiotherapy combination therapy was conducted in 106 advanced HNSCC patients, and showed a significant survival improvement for nimotuzumab treated patients [96].

Zalutumumab (Genmab; Copenhagen, Denmark) is a anti-EGFR mAb entirely humanized with high-affinity to EGFR. Twenty eight patients with metastatic/recurrent HNSCC were treated with zalutumumab and showed a response rate of only $7.1 \%$ and the most frequently adverse effects (AEs) reported in Phase I/II studies were infusionrelated reactions, rash/acne, and dyspnea [97]. Furthermore, 286 HNSCC patients resistant to platinum-based chemotherapy showed a significant improvement in PFS $(p=0.0012)$ when treated with zalutumumab, and a trend in improved OS (6.7 months vs. 5.2 months in zalutumab vs. control groups, respectively; HR, $0.77 ; 95 \% \mathrm{CI}, 0.57-1.05 ; P=0.0648$ ) [98]. Zalutumumab has also failed to show increased loco-regional control and 3-year disease specific or overall survival in another randomized phase III study (NCT00496652). This study was conducted by the Danish Head and Neck Cancer 
Consortium (DAHANCA) and aimed to evaluate if concurrent treatment with zalutumumab during RT improved outcomes in patients with HNSCC.

MEHD7945A (Roche, Genentech, South San Francisco, $\mathrm{CA}$ ), is a mAb against EGFR and HER3 that inhibits the binding of specific ligands dependent on EGFR- and HER3mediated downstream signaling [99]. This monoclonal antibody has modulated radiation responses in lung and head and HNSCC. Preclinical studies have demonstrated that MEHD7945A in combination with radiation is more cytotoxic in comparison to individual anti-EGFR or anti-HER3 antibodies using xenograft models. The dual EGFR/HER3 targeting action of MEHD7945A merits further investigation and clinical trial evaluation [100].

R05083945 (Roche, Genentech, South San Francisco, $\mathrm{CA}$ ) is a glyco-engineered anti-EGFR IgG1 mAb with a high affinity for all Fc $\gamma$ RIIIa variants. An antibody-dependent cellular cytotoxicity assay (ADCC) showed increased activity of RO5083945 compared to cetuximab and panitumumab. Preclinical approaches provided steps for the clinical trial recruitment. The pharmacodynamics investigation has been conducted in patients with KRAS mutated tumors in an open label multicenter in patients with operable HNSCC (Data not published; NCT01046266).

Sym004 (MerckKGaA) is a novel combination between 992 and 1024 antibodies, directed against different nonoverlapping epitopes in the extracellular domain of EGFR, with a superior anticancer efficacy compared with existing mAbs. Additionally, the antibody mixture showed a potent inhibition of cell growth, efficient inhibition of ligand binding and also the internalization and degradation of EGFR [101]. More recently, the efficacy and tolerability of Sym004, was investigated in recurrent and/or metastatic HNSCC patients (NCT01417936). The results showed moderate anti-tumor activity of Sym004 in patients (reduced disease progression at 6 months in $12 \%$ of patients). In addition, the safety profile of the Sym004 was comparable to other anti-EGFR mAbs [102]. For this reason, Sym004 represents a promise in treatment of HNSCC patients, mainly those that are cetuximab-refractory.

\subsection{Tyrosine Kinase Inhibitors -TKIs}

TKIs are small molecules that can bind directly into the adenosine triphosphate (ATP) of the tyrosine kinase domain (TKD), thus inhibiting the intracellular signaling pathways [103]. Currently, there are a variety of multi-targeted small molecule tyrosine kinase inhibitors under investigation in Phase II and III trials in different HNSCC therapeutic settings with the potential to significantly modify the approach to anti-EGFR therapy for HNSCC.

The first TKI approved by the FDA was gefitinib (Iressa ${ }^{\circledR}$, AstraZeneca, Inc.) for use in non-small-cell lung cancer (NSCLC) [104]. A Phase II study showed a tolerable cytotoxic action rate and a response to neoadjuvant treatment in $18 \%$ of 22 HNSCC patients [105]. Furthermore, the response rate (RR) was $10.6 \%$, median OS was 8.1 months, and 1-year OS rate was $29.2 \%$ in HNSCC patients $(n=52)$ with metastatic or recurrent disease and tolerable levels of AEs were reported [106].
Erlotinib (Genentech; South San Francisco, CA.), also known as Tarceva, ${ }^{\circledR}$ is a TKI FDA-approved as a first-line treatment for NSCLC for patients with exon 19 deletions or exon 21 (L858R) EGFR mutations [107]. A Phase II study conducted recently with 21 HNSCC patients, showed an increase of $63 \%$ in overall survival and few adverse events, after treatment with erlotinib, cisplatin and radiotherapy [108]. In recent years, these clinical studies have supported use of erlotinib with other chemotherapeutic agents by displaying an improvement in overall survival and acceptable levels of toxicity [109-111]. The effect of erlotinib monotherapy in combination with radiotherapy has been proposed as a Phase I/II trial (NCT00442455). So far, there is no published data on cytotoxicity and clinical effects of this combination. Everolimus, an inhibitor of mammalian target of rapamycin (mTOR), was combined with erlotinib in a clinical trial of patients with metastatic platinum-resistant HNSCC. This approach was based on the frequent activation of the mTOR pathway in HNSCC. Unfortunately, the trial showed little benefit, with a modest influence on immunosuppression and tumor growth [112]. Currently, a Phase II clinical trial is being conducted to evaluate the effect of docetaxel and cisplatin combination with or without erlotinib, and is currently recruiting participants (NCT01064479).

Lapatinib (GlaxoSmithKline Inc.) also known as Tykerb® is a reversible TKI with high affinity for the EGFR and HER2 receptor. Recently, this chemotherapy received FDA approval in combination with letrozole for patients with estrogen receptor and HER2, and in combination with capecitabine (Xeloda ${ }^{\circledR)}$ for patients with advanced breast cancer [113], Few studies have evaluated lapatinib alone or in combination, which may be explained by the low rate of HER2 receptor expression in HNSCC tumors [114]. However, there is evidence that the use of lapatinib prolongs tumor stabilization of salivary glands tumors at approximately 6 months (36\% - 62 patients) [115] and that combination with chemoradiotherapy increased the 6 month complete response rate postchemoradiotherapy [116]. Currently, there is one Phase II trial (NCI200901492) using the combination of lapatinib with capecitabine. Study objective include the evaluation of OS, PFS response rate, toxicity and quality of life. The THYHARD (NCT01711658) Phase II trial is recruiting HNSCC patients and evaluating the additive effects of radiotherapy plus cisplatin with or without lapatinib. Although lapatinib was initially considered a promising drug to treat HNSCC, a study testing adjuvant lapatinib in high-risk HNSCC after surgery was terminated early by the sponsor when outcomes between the placebo and lapatinib arms were not observed to be different (data not published; NCT00424255).

\section{RECENT PATENTS (NEW GENERATION OF TKIs)}

A variety of TKIs have been developed in recent years, and many of them tested in pre-clinical studies that show promising results against various tumor types. However, use is not approved for clinical use yet. Our review draws attention to promising chemotherapeutic agents in the treatment of HNSCC.

CUDC-101 (Curis, Inc.) 7-(4-(3-ethynylphenylamino)-7methoxyquinazolin-6-yloxy)-N-hydroxyheptanamide is a recently discovered reversible TKI that has multiple molecu- 
lar targets (EGFR, HER2 and HDAC). A preclinical trial demonstrated increased anti-proliferative activity of CUDC101 in HNSCC cell lines, when compared to exposure with erlotinib, lapatinib or vorinostat combination [117]. Recently, a Phase I trial, was conducted in twenty-five patients with advanced solid tumors who received incremental doses of CUDC-101. Preliminary evidence of antitumor activity was demonstrated with good tolerance levels [118]. Additionally, a Phase I trial was conducted in HNSCC to investigate the safety and pharmacokinetics of CUDC-101 in combination with cisplatin and radiation (data not published) (NCT01384799).

Icotinib (Zhejiang Beta Pharma Inc.) $[1,4,7,10]$ tetraoxacyclododecino[2,3-g]quinazolin-4-amine, $\quad \mathrm{N}-(3-$ ethynylphenyl)-7,8,10,11,13,14-hexahydro targets wild type and mutated EGFR variants (L858R, L861Q, T790M). The in vitro approach showed an increased anti-proliferative effect in A431 cell lines, while in in vivo studies, an antitumor effect was observed in nude mice of human tumor-derived xenografts [119]. Icotinib clinical trials, conducted in patients with advanced NSCLC, showed positive clinical antitumor activities and acceptable toxicity in monotherapy or in combination [120,121]. Although there are several clinical trials in other solid tumors such as NSCLC, esophageal and pancreatic cancers, there is only one Phase II clinical trial that is active but not recruiting patients with advanced nasopharyngeal carcinoma to evaluate the icotinib efficacy as a monotherapy (NCT02328261).

Irreversible TKIs covalently bind to a phosphorylationspecific site in the intramembrane portion of their target, blocking the phosphorylation and subsequent activation of intracellular pathways. This class of molecules is known as the second-generation irreversible tyrosine kinase inhibitor and some irreversible TKIs are in advanced stages of clinical and preclinical testing approaches.

Afatinib (Gilotrif®, Boehringer Ingelheim, Inc.)((E)-N[4-(3-chloro-4-fluoroanilino)-7-[(3S)-oxolan-3-

yl]oxyquinazolin-6-yl]-4-(dimethylamino)but-2-enamide

[122] (Fig. 2A) is an irreversible HER family inhibitor that targets EGFR, HER-2, and HER-4. The FDA approved afatinib as a first-line treatment of NSCLC patients with exon 19 deletions or exon 21 (L858R) EGFR mutations [123]. After promising results in NSCLC patients, a Phase III clinical trial (LUX-Head\&Neck) is being conducted in HNSCC patients to compare the efficacy and safety of afatinib as an adjuvant therapy for patients who have received definitive, concurrent cisplatin-based chemoradiotherapy. A recent phase II multicenter trial (NCT01538381), evaluated the intervention of the pre-operative activity of afatinib vs. nontreatment in HNSCC. Preliminary results demonstrated a tumor volume reduction assessed by FDGPET (18F-fluorodeoxyglucose-positron emission tomography). The association of afatinib and other chemotherapeutic agents has been evaluated in a clinical trial I/II (NCT01721525) investigating a new chemotherapy regimen based on two oral drugs and two intravenous drugs (Afatinib, Ribavirin and Carboplatin/Paclitaxel). The efficacy and safety of afatinib was recently demonstrated in the LUXHead\&Neck 1 trial. This is a Phase III, randomized, openlabel trial (NCT01345682) that evaluated afatinib efficacy and safety $v s$. methotrexate in 483 patients with recurrent or metastatic HNSCC after platinum-based therapy. Afatinib showed a significant increase in PFS $(p=0.030)$. Moreover it had a tolerable side effect profile [124].

AST1306 (Allist Pharmaceuticals Inc.), N-[4-[3-chloro4-[(3- fluorophenyl)methoxy]anilino]quinazolin-6-yl]prop-2enamide (Fig. 2B), also known as Allitinib, (B is a potent antiEGFR with irreversible action. In addition, it has an affinity for other EGFR family member proteins (HER2 and HER4) and exhibits significant antineoplastic activity in vitro and in vivo [125]. A recent clinical trial conducted in patients with solid tumors showed a preliminary anti-tumor effect and stable disease for $\geq 6$ months in 7 patients (ChiCTR-ONC10000893). Despite these promising results, AST1306 has not been tested in head and neck cancer patients.

PF-00299804 (Dacomitinib®, Pfizer Inc.) (E)-N-(4-(3chloro-4-fluorophenylamino)-7-methoxyquinazolin-6-yl)-4(piperidin-1-yl)but-2-enamide (Fig. 2C) is an irreversible pan-Her inhibitor with cytotoxicity activity in tumor xenograft models that express HER family members, and efficient inhibition in double EGFR (L858R/T790M) mutation [126]. Recently, a phase II trial showed positive results in metastatic HNSCC, in which $57 \%$ of patients (36/69) maintained stable disease and treatment had acceptable toxicity levels (NCT01737008) [127].

EKB-569 (Wyeth Inc.), (E)-N-(4-(3-chloro-4-fluorophenylamino)-3-cyano-7-ethoxyquinolin-6-yl)-4-(dimethylamino) but-2-enamide (Fig. 2D), also known as Pelitinib, ${ }^{\circledR}$ is an irreversible EGFR inhibitor that has shown potential antineoplastic effects in solid tumors [128]. Recently, a Phase I trial was conducted to determine the dosing for acceptable toxicity levels and induced therapy responses of EKB-559 [129]. Pre-clinical studies, using squamous cell carcinoma suggest that EKB-569 increases sensitivity to radiotherapy [130]. At present, no clinical trial has been conducted in HNSCC patients.

CNX-2006, (Clovis Oncology, Inc.) N-[3-[[2-[4-[[1-(2fluoroethyl)azetidin-3-yl]amino]-2-methoxyanilino]-5-(trifluoromethyl)pyrimidin-4-yl]amino]phenyl]prop-2-enamide (Fig. 2E) is an irreversible EGFR inhibitor that inhibits activating mutations of $E G F R$ with high affinity as well as cells harboring the T790M mutation [131]. Although, in initial stages few studies have been conducted with CNX-2006 in HNSCC models, we believe that clinical trials will soon follow due to its EGFR inhibitory potential.

AZD9291, (AstraZeneca. Inc.) N-[2-[2-(dimethylamino) ethyl-methylamino]-4-methoxy-5-[[4-(1-methylindol-3-yl)pyrimidin-2-yl]amino]phenyl]prop-2-enamide is a potent irreversible mutant-selective EGFR inhibitor also known as Osimertinib (Fig. 2F). Initially clinical trials with this inhibitor demonstrated a clinical benefit in lung cancer patients with a L858R/T790M EGFR mutation [132]. In November 2015, AZD9291 (Tagrisso ${ }^{\mathrm{TM}}$ ) was approved by the FDA for the treatment of patients with metastatic EGFR T790M mutation-positive NSCLC that was resistant to first-generation EGFR TKI therapy [133]. However, our search for this review did not any clinical and preclinical approaches in head and neck cancer. Due to its potent EGFR wild-type inhibi- 


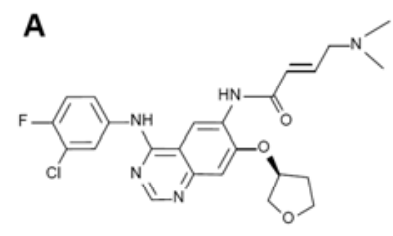

Afatinib

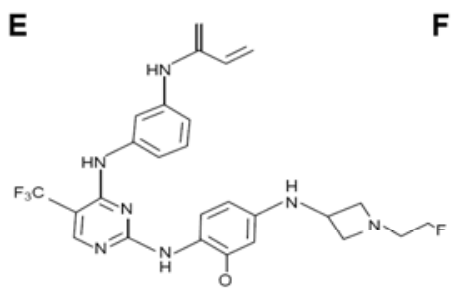

CNX-2006

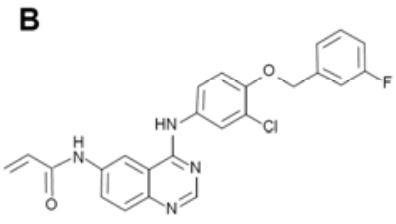

Allitinib

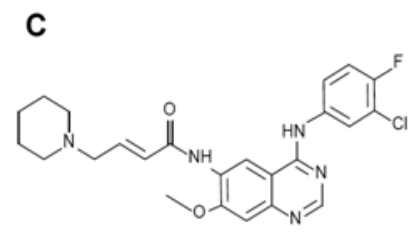

PF00299804

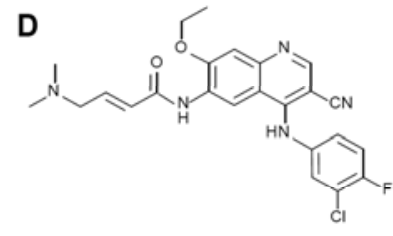

EKB-569

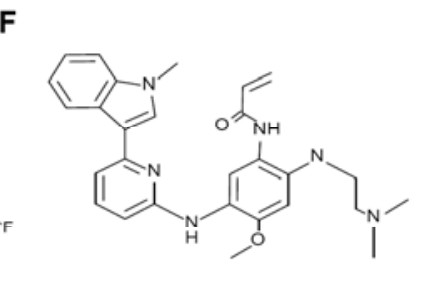

AZD9291
G

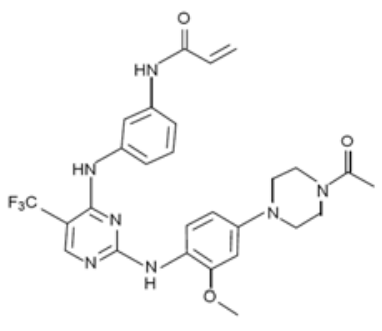

CO-1686

Fig. (2). Irreversible anti-EGFR molecules with therapeutic potential in head and neck cancer. A-Afatinib (Gilotrif ${ }^{\circledR}$ - Boehringer Ingelheim Pharmaceuticals, Inc. B- Allitinib (Allist Pharmaceuticals, Inc.); C- PF-00299804 (Dacomitinib ${ }^{\circledR}$ - Pfizer Inc); D- EKB-569 (Pelitinib ${ }^{\circledR}$ Wyeth Inc.); E- CNX-2006 (Clovis Oncology, Inc.); F- AZD9291 (AstraZeneca); G- CO-1686 (Rociletinib ${ }^{\circledR}$ - Clovis Oncology, Inc.)

tory action [134], AZD9291 may be a promising candidate in head neck cancer therapy.

CO-1686 (Clovis Oncology, Inc.) 2-propenamide, N-[3[[2-[4-(4-acetylpiperazin-1-yl)-2-methoxyanilino]-5-(trifluoromethyl)pyrimidin-4-yl]amino]phenyl]prop-2-enamide, also known as Rociletinib, ${ }^{\circledR}$ (Fig. 2G) is an irreversible inhibitor of EGFRwt and mutant-selective EGFR. The TIGER, I, II and III trials are recruiting patients with EGFR-mutated, advanced NSCLC after failure of at least one previous EGFR-directed TKI. The most recent clinical studies conducted in NSCLC patients treated with CO-1686 showed a positive tumor response and sustained disease control [135]. Although, CO-1686 has been demonstrating promising results in preclinical models, no clinical trial has been conducted in HNSCC.

Finally, EGFR antisense (EGFR AS) has been used in experimental models to evaluate its ability to inhibit the proliferation of HNSCC cell lines [136]. This approach consists of innoculating EGFR antisense that binds to specific mRNAs to interfere with the endogenous expression of EGFR. EGFR antisense results in a dysfunctional, mature protein, thereby reducing the activity of the ligand-binding domain and the kinase domain [136]. In nude mice xenografts, intratumoral plasmids that were injected with antisense EGFR sequences showed reduced tumor volumes when compared with the control group [137]. Subsequently, intralesional injections of EGFR liposomal antisense gene therapy in normal mice showed tolerable toxicity levels [138]. Based on the results, 17 patients with LAHNSCC were treated with intratumoral EGFR AS injections and afavorable clinical response was observed in $(5 / 17)$ of patients (29\%) [139].

\section{PREDICTIVE BIOMARKERS TO ANTI-EGFR THERAPY IN HNSCC}

Currently, the only anti-EGFR drug approved for HNSCC is cetuximab/panitumumab. A focus of great interest has been on the identification of predictive biomarkers of clinical response to these drugs $[140,141]$. Despite this rationale, a large body of evidence has showed that alteration of EGFR (protein overexpression, gene amplification) were not associated with patient response [141]. Intracellular pathways regulators, particularly, activating mutations of KRAS oncogene, were associated with mABs response [142]. The oncogene KRAS, drives signal transduction downstream of transmembrane receptor tyrosine kinases, especially the EGF receptor. However, KRAS mutations result in incessant activation of the intracellular RAS/MAPK/PI3K pathways, resulting in increased cell proliferation and survival, neoplastic transformation, cell migration and metastasis [143]. Hotspot KRAS activating mutations are recognized as strong predictors of resistance to EGFR-mAbs (cetuximab or panitumumab) in metastatic colorectal cancer (MCC) [142, 144, 145]. In the last few decades, some in vitro findings have associated the low response rate to mAbs with an overexpression of the PI3K/AKT/mTOR pathway [146]. A seminal retrospective study of MCC showed that KRAS, BRAF, $N R A S$, and PIK3CA exon 20 mutations were significantly associated with a low cetuximab response rate [147].

In HNSCC, no predictive molecular marker of response to anti-EGFR agents is known. KRAS mutations are very rare ( $<1 \%$ ), while EGFR mutations represent less than $5 \%$ of HNSCCs [24]. Thus, the mutational status of EGFR and $K R A S$ genes are not useful tools for predicting response to mAbs, due to low frequencies [148]. In HNSCC, other alterations may be associated with patient response, such as ligand levels, which have been associated to a few response rates for EGFR therapies. In vitro approaches in HNSCC cell lines, showed that the detection of values $>$ or $=20 \mathrm{pmol} / \mathrm{L}$ of amphiregulin are associated with increased efficiency of cetuximab and gefitinib, when compared to cell lines that have low amphiregulin expression [149]. These in vitro findings were observed in 47 patients with HNSCC in which high expression of amphiregulin demonstrated significantly shortened OS (HR: 2.2, p = 0.002) and PFS (HR 2.2, p = 0.019 ), compared with patients with low expression scores [150]. Other ligands such as HRG, have shown that signifi- 
cantly increased levels of expression in HNSCC patients is preferably associated with HER3 activation and defines a biologically distinct subset of patients, with a positive correlation with cetuximab/cisplatin response [151].

TGF- $\alpha$ overexpression, was implicated in cetuximab resistance in cell lines [152]. Interestingly, the whole expression profile of xenograft models using cetuximab-resistant colorectal cancer cell lines showed that phosphorylated MET was detected in resistant cell lines. The authors associate the increase in MET phosphorylation levels with TGF- $\alpha$ overexpression [152]. Regarding HNSCC, TGF- $\beta$ overexpression is related to de novo and acquired resistance to EGFR-targeted mAbs, and supply a rationale for TGF- $\beta$ combination therapies [153].

Another hypothesis suggests that, EGFR nuclear translocation is mediated by the Scr kinase family and overexpression of HER ligands (EGF, ARG, HB-EGF) leads to a cetuximab-resistant phenotype [79]. In HNSCC, EGFR nuclear translocation is associated with cetuximab/radiation therapeutic response. In this study, HNSCC cell lines treated with this combination showed elevated levels of nuclear EGFR and consequently a resistance phenotype, while Dasatinib therapy combination can inhibit EGFR translocation and restore cetuximab sensitivity [154].

\section{CURRENT \& FUTURE DEVELOPMENTS}

EGFR inhibitors represent a class of chemotherapeutic agents with promising results in monotherapy or in combination with other anticancer agents. HNSCC tumors frequently exhibit very high expression of EGFR and anti-EGFR, and Cetuximab is the only targeted therapy approved for HNSCC treatment. However, a subgroup of HNSCC patients demonstrate a response to cetuximab monotherapy, although the underlying mechanisms of this response remain ill-defined and there is no biomarker to predict responders.

The studies reported in this review reveal the potential of the newest generation of tyrosine kinase inhibitors, which are mainly being designed for the effective inhibition of the EGFR and other tyrosine kinase receptors simultaneouslys. Moreover, the development of multi-targeted therapies and irreversible anti-EGFR inhibitors reveals new perspectives in clinical trials and future treatment regimens. Thirdgeneration EGFR inhibitors, include afatinib, and is currently being tested in HNSCC patients. The multi-modality treatment adopted in HNSCC frequently impacts quality of life due to extensive surgeries and toxicities related to intensive chemo-radiation approaches. Targeted therapies are becoming increasingly adopted for the treatment of various tumor types due to their ability to adopt efficient and selective mechanisms of action, which limits cytotoxicity when compared to conventional chemotherapeutic agents. Thus, the evaluation of new generation tyrosine kinase inhibitors in clinical trials, which includes HNSCC patients, and the search for molecular markers that predict sensitivity to these drugs, are of great importance to successfully improve the treatment of these patients.

\section{CONFLICT OF INTEREST}

The authors confirm that this article content has no conflicts of interest.

\section{ACKNOWLEDGEMENTS}

The authors would like to acknowledge Dr. Laura Mussel white for critical revision of the manuscript. André L. Carvalho and Rui M. Reis have a National Counsel of Technological and Scientific Development (CNPq) scholarship. A.C.C, has a FAPESP (2013/13834-7) scholarship.

\section{REFERENCES}

[1] Ferlay J, Shin HR, Bray F, Forman D, Mathers C, Parkin DM. Estimates of worldwide burden of cancer in 2008: GLOBOCAN 2008. Int J Cancer 2010; 127(12): 2893-917.

[2] Jemal A, Bray F, Center MM, Ferlay J, Ward E, Forman D. Global cancer statistics. CA Cancer J Clin 2011; 61(2): 69-90.

[3] Torre LA, Bray F, Siegel RL, Ferlay J, Lortet-Tieulent J, Jemal A. Global cancer statistics, 2012. CA Cancer J Clin 2015; 65(2): 87108.

[4] Suh Y, Amelio I, Guerrero Urbano T, Tavassoli M. Clinical update on cancer: Molecular oncology of head and neck cancer. Cell Death Dis 2014; 5: e1018.

[5] Wong DT, Todd R, Tsuji T, Donoff RB. Molecular biology of human oral cancer. Crit Rev Oral Biol Med 1996; 7(4): 319-28.

[6] Janmaat ML, Giaccone G. The epidermal growth factor receptor pathway and its inhibition as anticancer therapy. Drugs today 2003; 39 Suppl C: $61-80$

[7] Jemal A, Siegel R, Xu J, Ward E. Cancer statistics, 2010. CA Cancer J Clin 2010; 60(5): 277-300.

[8] Haddad R, Annino D, Tishler RB. Multidisciplinary approach to cancer treatment: focus on head and neck cancer. Dent Clin N AM 2008; 52(1): 1-17, vii.

[9] Posner MR, Haddad RI, Wirth L, Norris CM, Goguen LA, Mahadevan A, et al. Induction chemotherapy in locally advanced squamous cell cancer of the head and neck: Evolution of the sequential treatment approach. Semin Oncol 2004; 31(6): 778-85.

[10] Budach V. TPF sequential therapy: when and for whom? Oncologist 2010; 15 Suppl 3: 13-8.

[11] Blot WJ, McLaughlin JK, Winn DM, Austin DF, Greenberg RS, Preston-Martin S, et al. Smoking and drinking in relation to oral and pharyngeal cancer. Cancer Res 1988; 48(11): 3282-7.

[12] D'Souza G, Agrawal Y, Halpern J, Bodison S, Gillison ML. Oral sexual behaviors associated with prevalent oral human papillomavirus infection. J Infect Dis 2009; 199(9): 1263-9.

[13] Brennan JA, Boyle JO, Koch WM, Goodman SN, Hruban RH, Eby YJ, et al. Association between cigarette smoking and mutation of the p53 gene in squamous-cell carcinoma of the head and neck. N Eng J Med 1995; 332(11): 712-7.

[14] Pai SI, Westra WH. Molecular pathology of head and neck cancer: implications for diagnosis, prognosis, and treatment. Annu Rev Pathol 2009; 4: 49-70.

[15] Talamini R, Bosetti C, La Vecchia C, Dal Maso L, Levi F, Bidoli $\mathrm{E}$, et al. Combined effect of tobacco and alcohol on laryngeal cancer risk: A case-control study. Cancer Causes Control 2002; 13(10): 957-64.

[16] Brooks PJ, Zakhari S. Acetaldehyde and the genome: Beyond nuclear DNA adducts and carcinogenesis. Environ Mol Mutagen 2014; 55(2): 77-91.

[17] Kreimer AR, Clifford GM, Boyle P, Franceschi S. Human papillomavirus types in head and neck squamous cell carcinomas worldwide: A systematic review. Cancer Epidemiol Biomarkers Prev 2005; 14(2): 467-75

[18] Chaturvedi AK, Engels EA, Pfeiffer RM, Hernandez BY, Xiao W, Kim E, et al. Human papillomavirus and rising oropharyngeal cancer incidence in the United States. J Clin Oncol 2011; 29(32): 4294-301.

[19] Gillison ML, Koch WM, Capone RB, Spafford M, Westra WH, $\mathrm{Wu} \mathrm{L}$, et al. Evidence for a causal association between human papillomavirus and a subset of head and neck cancers. J Natl Cancer Inst 2000; 92(9): 709-20.

[20] Klussmann JP, Weissenborn SJ, Wieland U, Dries V, Kolligs J, Jungehuelsing $\mathrm{M}$, et al. Prevalence, distribution, and viral load of human papillomavirus 16 DNA in tonsillar carcinomas. Cancer 2001; 92(11): 2875-84.

[21] Parkin DM, Bray F, Ferlay J, Pisani P. Global cancer statistics, 2002. CA Cancer J Clin. 2005; 55(2): 74-108. 
[22] Siegel R, Naishadham D, Jemal A. Cancer statistics, 2012. CA Cancer J Clin. 2012; 62(1): 10-29.

[23] Zur Hausen H. Papilloma viruses in the causation of human cancers - A brief historical account. Virology 2009; 384(2): 260-5.

[24] Cancer Genome Atlas N. Comprehensive genomic characterization of head and neck squamous cell carcinomas. Nature. 2015; 517(7536): 576-82.

[25] Lui VW, Hedberg ML, Li H, Vangara BS, Pendleton K, Zeng Y, et al. Frequent mutation of the PI3K pathway in head and neck cancer defines predictive biomarkers. Cancer Discov 2013; 3(7): 761-9.

[26] Stransky N, Egloff AM, Tward AD, Kostic AD, Cibulskis K, Sivachenko A, et al. The mutational landscape of head and neck squamous cell carcinoma. Science 2011;333(6046): 1157-60.

[27] Agrawal N, Frederick MJ, Pickering CR, Bettegowda C, Chang K, $\mathrm{Li} \mathrm{RJ}$, et al. Exome sequencing of head and neck squamous cell carcinoma reveals inactivating mutations in NOTCH1. Science. 2011; 333(6046): 1154-7.

[28] Pickering CR, Zhang J, Yoo SY, Bengtsson L, Moorthy S, Neskey $\mathrm{DM}$, et al. Integrative genomic characterization of oral squamous cell carcinoma identifies frequent somatic drivers. Cancer Discov 2013; 3(7): 770-81.

[29] Mountzios G, Rampias T, Psyrri A. The mutational spectrum of squamous-cell carcinoma of the head and neck: Targetable genetic events and clinical impact. Ann Oncology 2014; 25(10): 1889-900.

[30] Egloff AM, Grandis J. Epidermal growth factor receptor-targeted molecular therapeutics for head and neck squamous cell carcinoma. Expert Opin Ther Targets 2006; 10(5): 639-47.

[31] Chung CH, Ely K, McGavran L, Varella-Garcia M, Parker J, Parker $\mathrm{N}$, et al. Increased epidermal growth factor receptor gene copy number is associated with poor prognosis in head and neck squamous cell carcinomas. J Clin Oncol 2006; 24(25): 4170-6.

[32] Cancer Genome Atlas Research N. Comprehensive molecular profiling of lung adenocarcinoma. Nature 2014; 511(7511): 54350

[33] Cancer Genome Atlas N. Comprehensive molecular characterization of human colon and rectal cancer. Nature 2012; 487(7407): 330-7.

[34] Bonner JA, Harari PM, Giralt J, Azarnia N, Shin DM, Cohen RB, et al. Radiotherapy plus cetuximab for squamous-cell carcinoma of the head and neck. N Eng J Med 2006; 354(6): 567-78.

[35] Vermorken JB, Trigo J, Hitt R, Koralewski P, Diaz-Rubio E, Rolland $\mathrm{F}$, et al. Open-label, uncontrolled, multicenter Phase II study to evaluate the efficacy and toxicity of cetuximab as a single agent in patients with recurrent and/or metastatic squamous cell carcinoma of the head and neck who failed to respond to platinumbased therapy. J Clin Oncol 2007; 25(16): 2171-7.

[36] Cohen MH, Chen H, Shord S, Fuchs C, He K, Zhao H, et al. Approval summary: Cetuximab in combination with cisplatin or carboplatin and 5-fluorouracil for the first-line treatment of patients with recurrent locoregional or metastatic squamous cell head and neck cancer. Oncologist 2013; 18(4): 460-6.

[37] Savage CR, Jr., Inagami T, Cohen S. The primary structure of epidermal growth factor. J Biol Chem 1972; 247(23): 7612-21.

[38] Cohen S, Carpenter G, King L, Jr. Epidermal growth factorreceptor-protein kinase interactions. Co-purification of receptor and epidermal growth factor-enhanced phosphorylation activity. J Biol Chem 1980; 255(10): 4834-42.

[39] Garrett TP, McKern NM, Lou M, Elleman TC, Adams TE, Lovrecz $\mathrm{GO}$, et al. Crystal structure of a truncated epidermal growth factor receptor extracellular domain bound to transforming growth factor alpha. Cell 2002; 110(6): 763-73

[40] Yarden Y, Sliwkowski MX. Untangling the ErbB signalling network. Nat Rev Mol Cell Biol 2001; 2(2): 127-37.

[41] Greenfield C, Hiles I, Waterfield MD, Federwisch M, Wollmer A, Blundell TL, et al. Epidermal growth factor binding induces a conformational change in the external domain of its receptor. EMBO J 1989; 8(13): 4115-23.

[42] Alroy I, Yarden Y. The ErbB signaling network in embryogenesis and oncogenesis: signal diversification through combinatorial ligand-receptor interactions. FEBS lett 1997; 410(1): 83-6.

[43] Vivanco I, Sawyers CL. The phosphatidylinositol 3-Kinase AKT pathway in human cancer. Nat Rev Cancer 2002; 2(7): 489-501.

[44] Silva CM. Role of STATs as downstream signal transducers in Src family kinase-mediated tumorigenesis. Oncogene 2004; 23(48): 8017-23.
[45] Normanno N, De Luca A, Bianco C, Strizzi L, Mancino M, Maiello MR, et al. Epidermal growth factor receptor (EGFR) signaling in cancer. Gene 2006; 366(1): 2-16.

[46] Mehra R, Serebriiskii IG, Dunbrack RL, Jr., Robinson MK, Burtness B, Golemis EA. Protein-intrinsic and signaling network-based sources of resistance to EGFR- and ErbB family-targeted therapies in head and neck cancer. Drug Resist Updat 2011; 14(6): 260-79.

[47] Keren S, Shoude Z, Lu Z, Beibei Y. Role of EGFR as a prognostic factor for survival in head and neck cancer: A meta-analysis. Tumour Biol 2014; 35(3): 2285-95.

[48] Normanno N, Bianco C, Strizzi L, Mancino M, Maiello MR, De Luca A, et al. The ErbB receptors and their ligands in cancer: An overview. Curr Drug Targets 2005; 6(3): 243-57.

[49] O-charoenrat P, Rhys-Evans PH, Modjtahedi H, Eccles SA. The role of c-erbB receptors and ligands in head and neck squamous cell carcinoma. Oral Oncol 2002; 38(7): 627-40.

[50] Grandis JR, Chakraborty A, Zeng Q, Melhem MF, Tweardy DJ. Downmodulation of TGF-alpha protein expression with antisense oligonucleotides inhibits proliferation of head and neck squamous carcinoma but not normal mucosal epithelial cells. J Cell Biochem 1998; 69(1): 55-62.

[51] Aupperlee MD, Leipprandt JR, Bennett JM, Schwartz RC, Haslam SZ. Amphiregulin mediates progesterone-induced mammary ductal development during puberty. Breast Cancer Res 2013; 15(3): R44.

[52] Busser B, Sancey L, Brambilla E, Coll JL, Hurbin A. The multiple roles of amphiregulin in human cancer. Biochim Biophys Acta 2011; 1816(2): 119-31.

[53] Nanba D, Higashiyama S. Dual intracellular signaling by proteolytic cleavage of membrane-anchored heparin-binding EGF-like growth factor. Cytokine Growth Factor Rev 2004; 15(1): 13-9.

[54] Miyamoto S, Yagi H, Yotsumoto F, Kawarabayashi T, Mekada E. Heparin-binding epidermal growth factor-like growth factor as a novel targeting molecule for cancer therapy. Cancer Sci 2006; 97(5): $341-7$

[55] Ito Y, Higashiyama S, Takeda T, Yamamoto Y, Wakasa KI, Matsuura N. Expression of heparin-binding epidermal growth factorlike growth factor in pancreatic adenocarcinoma. Int J Pancreatol 2001; 29(1): 47-52.

[56] Revillion F, Lhotellier V, Hornez L, Bonneterre J, Peyrat JP. ErbB/HER ligands in human breast cancer, and relationships with their receptors, the bio-pathological features and prognosis. Ann Oncol 2008; 19(1): 73-80

[57] Yotsumoto F, Yagi H, Suzuki SO, Oki E, Tsujioka H, Hachisuga T, et al. Validation of HB-EGF and amphiregulin as targets for human cancer therapy. Biochem Biophys Res Commun 2008; 365(3): 55561.

[58] Reis-Filho JS, Pinheiro C, Lambros MB, Milanezi F, Carvalho S, Savage $\mathrm{K}$, et al. EGFR amplification and lack of activating mutations in metaplastic breast carcinomas. J Pathol 2006; 209(4): 44553.

[59] Maire CL, Ligon KL. Molecular pathologic diagnosis of epidermal growth factor receptor. Neuro-Oncol 2014; 16 Suppl 8: viii1-6.

[60] Hegi ME, Rajakannu P, Weller M. Epidermal growth factor receptor: a re-emerging target in glioblastoma. Curr Opin Neurol 2012; 25(6): 774-9.

[61] Saif MW. Colorectal cancer in review: the role of the EGFR pathway. Exp Opin Investig Drugs 2010; 19(3): 357-69.

[62] Okines A, Cunningham D, Chau I. Targeting the human EGFR family in esophagogastric cancer. Nat Rev Clin Oncol 2011; 8(8): 492-503.

[63] Rajkumar T, Gullick WJ. The type I growth factor receptors in human breast cancer. Breast cancer Res Treat 1994; 29(1): 3-9.

[64] Troiani T, Martinelli E, Capasso A, Morgillo F, Orditura M, De Vita $\mathrm{F}$, et al. Targeting EGFR in pancreatic cancer treatment. Curr Drug Targets 2012; 13(6): 802-10.

[65] Gazdar AF. Activating and resistance mutations of EGFR in nonsmall-cell lung cancer: Role in clinical response to EGFR tyrosine kinase inhibitors. Oncogene 2009; 28 Suppl 1: S24-31.

[66] Sheikh Ali MA, Gunduz M, Nagatsuka H, Gunduz E, Cengiz B, Fukushima $\mathrm{K}$, et al. Expression and mutation analysis of epidermal growth factor receptor in head and neck squamous cell carcinoma. Cancer science 2008; 99(8): 1589-94.

[67] Willmore-Payne C, Holden JA, Layfield LJ. Detection of EGFRand HER2-activating mutations in squamous cell carcinoma in volving the head and neck. Mod Pathol 2006; 19(5): 634-40. 
[68] Barretina J, Caponigro G, Stransky N, Venkatesan K, Margolin AA, Kim S, et al. The Cancer Cell Line Encyclopedia enables predictive modelling of anticancer drug sensitivity. Nature. 2012; 483(7391): 603-7.

[69] Johnson H, Del Rosario AM, Bryson BD, Schroeder MA, Sarkaria JN, White FM. Molecular characterization of EGFR and EGFRvIII signaling networks in human glioblastoma tumor xenografts. Mol Cell proteomics 2012; 11(12): 1724-40.

[70] Prigent SA, Nagane M, Lin H, Huvar I, Boss GR, Feramisco JR, et al. Enhanced tumorigenic behavior of glioblastoma cells expressing a truncated epidermal growth factor receptor is mediated through the Ras-Shc-Grb2 pathway. J Biol Chem 1996; 271(41): 25639-45.

[71] Sok JC, Coppelli FM, Thomas SM, Lango MN, Xi S, Hunt JL, et al. Mutant epidermal growth factor receptor (EGFRvIII) contributes to head and neck cancer growth and resistance to EGFR targeting. Clin Cancer Res 2006; 12(17): 5064-73.

[72] Melchers LJ, Clausen MJ, Mastik MF, Slagter-Menkema L, Langendijk JA, van der Laan BF, et al. Head and neck squamous cell carcinomas do not express EGFRvIII. Int J Radiat Oncol Biol Phys 2014; 90(2): 454-62.

[73] Nagalakshmi K, Jamil K, Pingali U, Reddy MV, Attili SS. Epider$\mathrm{mal}$ growth factor receptor (EGFR) mutations as biomarker for head and neck squamous cell carcinomas (HNSCC). Biomarkers 2014; 19(3): 198-206.

[74] Khattri A, Zuo Z, Bragelmann J, Keck MK, El Dinali M, Brown $\mathrm{CD}$, et al. Rare occurrence of EGFRvIII deletion in head and neck squamous cell carcinoma. Oral Oncol. 2015; 51(1): 53-8.

[75] Marti U, Hug M. Acinar and cellular distribution and mRNA expression of the epidermal growth factor receptor are changed during liver regeneration. J Hepatol 1995; 23(3): 318-27.

[76] Zimmermann H, Ganz P, Zimmermann A, Oguey D, Marti U, Reichen J. The overexpression of proliferating cell nuclear antigen in biliary cirrhosis in the rat and its relationship with epidermal growth factor receptor. J Hepatol 1995; 23(4): 459-64.

[77] Strambio-De-Castillia C, Niepel M, Rout MP. The nuclear pore complex: bridging nuclear transport and gene regulation. Nature reviews Mol Cell Biol 2010; 11(7): 490-501.

[78] Lin SY, Makino K, Xia W, Matin A, Wen Y, Kwong KY, et al. Nuclear localization of EGF receptor and its potential new role as a transcription factor. Nat Cell Biol 2001; 3(9): 802-8.

[79] Li C, Iida M, Dunn EF, Ghia AJ, Wheeler DL. Nuclear EGFR contributes to acquired resistance to cetuximab. Oncogene 2009; 28(43): 3801-13

[80] Brand TM, Iida M, Luthar N, Starr MM, Huppert EJ, Wheeler DL. Nuclear EGFR as a molecular target in cancer. Radiother Oncol 2013; 108(3): 370-7.

[81] Iida M, Brand TM, Campbell DA, Li C, Wheeler DL. Yes and Lyn play a role in nuclear translocation of the epidermal growth factor receptor. Oncogene 2013; 32(6): 759-67.

[82] van Dijk LK, Yim CB, Franssen GM, Kaanders JH, Rajander J, Solin O, et al. PET of EGFR with (64) Cu-cetuximab-F(ab')2 in mice with head and neck squamous cell carcinoma xenografts. Contrast Media Mol Imaging 2016; 11(1): 65-70.

[83] van Dijk LK, Boerman OC, Franssen GM, Lok J, Kaanders JH, Bussink J. Early response monitoring with 18F-FDG PET and cetuximab-F(ab')2-SPECT after radiotherapy of human head and neck squamous cell carcinomas in a mouse model. J Nucl Med 2014; 55(10): 1665-70.

[84] Liccardi G, Hartley JA, Hochhauser D. EGFR nuclear translocation modulates DNA repair following cisplatin and ionizing radiation treatment. Cancer Res 2011; 71(3): 1103-14.

[85] van Dijk LK, Boerman OC, Kaanders JH, Bussink J. PET Imaging in Head and Neck Cancer Patients to Monitor Treatment Response: A Future Role for EGFR-Targeted Imaging. Clin Cancer Res 2015; 21(16): 3602-9.

[86] Humblet Y. Cetuximab: an $\operatorname{IgG}(1)$ monoclonal antibody for the treatment of epidermal growth factor receptor-expressing tumours. Expert Opin Pharmacother 2004; 5(7): 1621-33.

[87] Harding J, Burtness B. Cetuximab: an epidermal growth factor receptor chemeric human-murine monoclonal antibody. Drugs Today 2005; 41(2): 107-27.

[88] Dai W, Li Y, Zhou Q, Xu Z, Sun C, Tan X, et al. Cetuximab inhibits oral squamous cell carcinoma invasion and metastasis via degradation of epidermal growth factor receptor. J Oral Pathol Med 2013.

[89] Goldberg RM. Cetuximab. Nat Rev Drug Disc 2005; Suppl: S10-1.
[90] Blick SK, Scott LJ. Cetuximab: a review of its use in squamous cell carcinoma of the head and neck and metastatic colorectal cancer. Drugs 2007; 67(17): 2585-607.

[91] Vermorken JB, Mesia R, Rivera F, Remenar E, Kawecki A, Rottey $\mathrm{S}$, et al. Platinum-based chemotherapy plus cetuximab in head and neck cancer. N Eng J Med 2008; 359(11): 1116-27.

[92] Burtness B, Goldwasser MA, Flood W, Mattar B, Forastiere AA, Eastern Cooperative Oncology G. Phase III randomized trial of cisplatin plus placebo compared with cisplatin plus cetuximab in metastatic/recurrent head and neck cancer: an Eastern Cooperative Oncology Group study. J Clin Oncol 2005; 23(34): 8646-54.

[93] Vermorken JB, Stohlmacher-Williams J, Davidenko I, Licitra L, Winquist E, Villanueva C, et al. Cisplatin and fluorouracil with or without panitumumab in patients with recurrent or metastatic squamous-cell carcinoma of the head and neck (SPECTRUM): an open-label Phase 3 randomised trial. Lancet Oncol 2013; 14(8): 697-710.

[94] Rojo F, Gracias E, Villena N, Cruz T, Corominas JM, Corradino I, et al. Pharmacodynamic trial of nimotuzumab in unresectable squamous cell carcinoma of the head and neck: A SENDO Foundation study. Clin Cancer Res 2010; 16(8): 2474-82.

[95] [cited 2013 25/11/2013]. Available from: http://clinicaltrials.gov/ ct2/home.

[96] Rodriguez MO, Rivero TC, del Castillo Bahi R, Muchuli CR, Bilbao MA, Vinageras EN, et al. Nimotuzumab plus radiotherapy for unresectable squamous-cell carcinoma of the head and neck. Cancer Biol Ther 2010; 9(5): 343-9.

[97] Bastholt L, Specht L, Jensen K, Brun E, Loft A, Petersen J, et al. Phase I/II clinical and pharmacokinetic study evaluating a fully human monoclonal antibody against EGFr (HuMax-EGFr) in patients with advanced squamous cell carcinoma of the head and neck. Radiother Oncol 2007; 85(1): 24-8.

[98] Machiels JP, Subramanian S, Ruzsa A, Repassy G, Lifirenko I, Flygare A, et al. Zalutumumab plus best supportive care versus best supportive care alone in patients with recurrent or metastatic squamous-cell carcinoma of the head and neck after failure of platinum-based chemotherapy: An open-label, randomised phase 3 trial. lancet Oncol 2011; 12(4): 333-43.

[99] Schaefer G, Haber L, Crocker LM, Shia S, Shao L, Dowbenko D, et al. A two-in-one antibody against HER3 and EGFR has superior inhibitory activity compared with monospecific antibodies. Cancer cell 2011; 20(4): 472-86.

[100] Li C, Huang S, Armstrong EA, Francis DM, Werner LR, Sliwkowski MX, et al. Antitumor effects of MEHD7945A, a dual specific antibody against EGFR and HER3, in combination with radiation in lung and head and neck cancers. Mol Cancer Ther 2015.

[101] Pedersen MW, Jacobsen HJ, Koefoed K, Hey A, Pyke C, Haurum JS, et al. Sym004: a novel synergistic anti-epidermal growth factor receptor antibody mixture with superior anticancer efficacy. Cancer Res 2010; 70(2): 588-97.

[102] Machiels JP, Specenier P, Krauss J, Dietz A, Kaminsky MC, Lalami Y, et al. A proof of concept trial of the anti-EGFR antibody mixture Sym004 in patients with squamous cell carcinoma of the head and neck. Cancer Chemother Pharmacol 2015; 76(1): 13-20.

[103] Ward WH, Cook PN, Slater AM, Davies DH, Holdgate GA, Green LR. Epidermal growth factor receptor tyrosine kinase. Investigation of catalytic mechanism, structure-based searching and discovery of a potent inhibitor. Biochem Pharmacol 1994; 48(4): 659-66.

[104] Lynch TJ, Bell DW, Sordella R, Gurubhagavatula S, Okimoto RA, Brannigan BW, et al. Activating mutations in the epidermal growth factor receptor underlying responsiveness of non-small-cell lung cancer to gefitinib. N Eng J Med 2004; 350(21): 2129-39.

[105] Lewis CM, Glisson BS, Feng L, Wan F, Tang X, Wistuba, II, et al. A phase II study of gefitinib for aggressive cutaneous squamous cell carcinoma of the head and neck. Clin Cancer Res 2012; 18(5): 1435-46.

[106] Cohen EE, Rosen F, Stadler WM, Recant W, Stenson K, Huo D, et al. Phase II trial of ZD1839 in recurrent or metastatic squamous cell carcinoma of the head and neck. J Clin Oncol 2003; 21(10): 1980-7.

[107] Cohen MH, Johnson JR, Chattopadhyay S, Tang S, Justice R, Sridhara R, et al. Approval summary: erlotinib maintenance therapy of advanced/metastatic non-small cell lung cancer (NSCLC). Oncologist 2010; 15(12): 1344-51. 
[108] Rao K, Kalapurakal S, Chalasani P, Robinson K, Malone J, Clausen $\mathrm{C}$, et al. A phase II study of intra-arterial cisplatin with concurrent radiation and erlotinib for locally advanced head and neck cancer. Cancer Chemother Pharmacol 2013; 72(3): 545-52.

[109] Arias de la Vega F, Contreras J, de Las Heras M, de la Torre A, Arrazubi V, Herruzo I, et al. Erlotinib and chemoradiation in patients with surgically resected locally advanced squamous cell carcinoma of the head and neck: a GICOR phase I trial. Annals of On$\operatorname{col} 2012 ; 23(4)$ : 1005-9.

[110] Li G, Hu W, Wang J, Deng X, Zhang P, Zhang X, et al. Phase II study of concurrent chemoradiation in combination with erlotinib for locally advanced esophageal carcinoma. Int J Radiat Oncol Biol Phys 2010; 78(5): 1407-12.

[111] Gilbert J, Rudek MA, Higgins MJ, Zhao M, Bienvenu S, Tsottles $\mathrm{N}$, et al. A phase I trial of erlotinib and concurrent chemoradiotherapy for stage III and IV (M0) squamous cell carcinoma of the head and neck. Clin Cancer Res 2012; 18(6): 1735-42.

[112] Massarelli E, Lin H, Ginsberg LE, Tran HT, Lee JJ, Canales JR, et al. Phase II trial of everolimus and erlotinib in patients with platinum-resistant recurrent and/or metastatic head and neck squamous cell carcinoma. Annals of Oncol 2015; 26(7): 1476-80.

[113] Bauerfeind I, Elling D, Heinemann V. Lapatinib in the Treatment of Hormone Receptor-Positive/ErbB2-Positive Breast Cancer. Breast care 2010; 5(s1): 13-5.

[114] Ali MA, Gunduz M, Gunduz E, Tamamura R, Beder LB, Katase N, et al. Expression and mutation analysis of her2 in head and neck squamous cell carcinoma. Cancer Invest 2010; 28(5): 495-500.

[115] Agulnik M, Cohen EW, Cohen RB, Chen EX, Vokes EE, Hotte SJ, et al. Phase II study of lapatinib in recurrent or metastatic epidermal growth factor receptor and/or erbB2 expressing adenoid cystic carcinoma and non adenoid cystic carcinoma malignant tumors of the salivary glands. J Clin Oncol 2007; 25(25): 3978-84.

[116] Harrington K, Berrier A, Robinson M, Remenar E, Housset M, de Mendoza FH, et al. Randomised Phase II study of oral lapatinib combined with chemoradiotherapy in patients with advanced squamous cell carcinoma of the head and neck: rationale for future randomised trials in human papilloma virus-negative disease. Eur $\mathbf{J}$ Cancer 2013; 49(7): 1609-18.

[117] Cai X, Zhai HX, Wang J, Forrester J, Qu H, Yin L, et al. Discovery of 7-(4-(3-ethynylphenylamino)-7-methoxyquinazolin-6-yloxy)-Nhydroxyheptanamide (CUDc-101) as a potent multi-acting HDAC, EGFR, and HER2 inhibitor for the treatment of cancer. J Med Chem 2010; 53(5): 2000-9.

[118] Shimizu T, LoRusso PM, Papadopoulos KP, Patnaik A, Beeram M, Smith LS, et al. Phase I first-in-human study of CUDC-101, a multitargeted inhibitor of HDACs, EGFR, and HER2 in patients with advanced solid tumors. Clin Cancer Res 2014; 20(19): 5032-40.

[119] Tan F, Shen X, Wang D, Xie G, Zhang X, Ding L, et al. Icotinib (BPI-2009H), a novel EGFR tyrosine kinase inhibitor, displays potent efficacy in preclinical studies. Lung cancer 2012; 76(2): 17782

[120] Li X, Yang XJ, Sun YF, Qin N, Lu JL, Wu YH, et al. [Clinical observation of icotinib hydrochloride for patients with advanced non-small cell lung cancer]. Chinese J Oncol 2012; 34(8): 627-31.

[121] Shi Y, Zhang L, Liu X, Zhou C, Zhang L, Zhang S, et al. Icotinib versus gefitinib in previously treated advanced non-small-cell lung cancer (ICOGEN): a randomised, double-blind phase 3 noninferiority trial. Lancet Oncol 2013; 14(10): 953-61.

[122] Bruns, A., Eichner, S., Lehmann, F., Albrecht, W., Maier, A. Crystalline forms of afatinib di-maleate. WO2013052157 (2013).

[123] Minkovsky N, Berezov A. BIBW-2992, a dual receptor tyrosine kinase inhibitor for the treatment of solid tumors. Current Opin Invest Drugs 2008; 9(12): 1336-46.

[124] Machiels JP, Haddad RI, Fayette J, Licitra LF, Tahara M, Vermorken JB, et al. Afatinib versus methotrexate as second-line treatment in patients with recurrent or metastatic squamous-cell carcinoma of the head and neck progressing on or after platinumbased therapy (LUX-Head \& Neck 1): An open-label, randomised phase 3 trial. Lancet Oncol 2015; 16(5): 583-94.

[125] Xie H, Lin L, Tong L, Jiang Y, Zheng M, Chen Z, et al. AST1306, a novel irreversible inhibitor of the epidermal growth factor receptor 1 and 2, exhibits antitumor activity both in vitro and in vivo. PloS one. 2011; 6(7): e21487.

[126] Gonzales AJ, Hook KE, Althaus IW, Ellis PA, Trachet E, Delaney AM, et al. Antitumor activity and pharmacokinetic properties of
PF-00299804, a second-generation irreversible pan-erbB receptor tyrosine kinase inhibitor. Mol Cancer Ther 2008; 7(7): 1880-9.

[127] Abdul Razak AR, Soulieres D, Laurie SA, Hotte SJ, Singh S, Winquist E, et al. A phase II trial of dacomitinib, an oral pan-human EGF receptor (HER) inhibitor, as first-line treatment in recurrent and/or metastatic squamous-cell carcinoma of the head and neck. Annals of Oncol 2013; 24(3): 761-9.

[128] Nunes M, Shi C, Greenberger LM. Phosphorylation of extracellular signal-regulated kinase 1 and 2, protein kinase $\mathrm{B}$, and signal transducer and activator of transcription 3 are differently inhibited by an epidermal growth factor receptor inhibitor, EKB-569, in tumor cells and normal human keratinocytes. Mol Cancer Ther 2004; 3(1): 21-7.

[129] Bryce AH, Rao R, Sarkaria J, Reid JM, Qi Y, Qin R, et al. Phase I study of temsirolimus in combination with EKB-569 in patients with advanced solid tumors. Invest N Drugs 2012; 30(5): 1934-41.

[130] Aravindan N, Thomas CR, Jr., Aravindan S, Mohan AS, Veeraraghavan J, Natarajan M. Irreversible EGFR inhibitor EKB-569 targets low-LET gamma-radiation-triggered rel orchestration and potentiates cell death in squamous cell carcinoma. PloS One. 2011; 6(12): e29705.

[131] Kadoaki Ohashi KS, Jing Sun, Yumei Pan, Annette O. Walter, Alex Dubrovskiy, Robert Tjin, Tetsuya Mitsudomi, William Pao. CNX-2006, a novel irreversible epidermal growth factor receptor (EGFR) inhibitor, selectively inhibits EGFR T790M and fails to induce T790M-mediated resistance in vitro. 2013 [cited 2014] Available from: http://www.clovisoncology.com/files/AACR 2013_Jing_CNX-2006_poster_2101A.pdf.

[132] Cross DA, Ashton SE, Ghiorghiu S, Eberlein C, Nebhan CA, Spitzler PJ, et al. AZD9291, an Irreversible EGFR TKI, Overcomes T790M-Mediated Resistance to EGFR Inhibitors in Lung Cancer. Cancer Discov 2014; 4(9): 1046-61.

[133] Greig SL. Osimertinib: First Global Approval. Drugs 2016; 76(2): 263-73.

[134] Butterworth, S., Finlay, M.R.V., Ward, R.A., Kadambar, V.K., Chandrashekar, R.C., Murugan, A., Redfearn, H.M. 2 - (2, 4, 5 substituted -anilino) pyrimidine derivatives as egfr modulators useful for treating cancer. WO2013014448 (2013).

[135] Sequist LV, Soria JC, Goldman JW, Wakelee HA, Gadgeel SM, Varga A, et al. Rociletinib in EGFR-mutated non-small-cell lung cancer. N Eng J Med 2015; 372(18): 1700-9.

[136] Rubin Grandis J, Chakraborty A, Melhem MF, Zeng Q, Tweardy DJ. Inhibition of epidermal growth factor receptor gene expression and function decreases proliferation of head and neck squamous carcinoma but not normal mucosal epithelial cells. Oncogene 1997 ; 15(4): 409-16.

[137] He Y, Zeng Q, Drenning SD, Melhem MF, Tweardy DJ, Huang L, et al. Inhibition of human squamous cell carcinoma growth in vivo by epidermal growth factor receptor antisense RNA transcribed from the U6 promoter. J Nat Cancer Inst 1998; 90(14): 1080-7.

[138] Zeng Q, Kanter PM, Dhir R, Gooding WE, Huang L, Grandis JR. Lack of toxicity of EGFR antisense gene therapy. J Exp Ther Oncol 2002; 2(3): 174-86.

[139] Lai SY, Koppikar P, Thomas SM, Childs EE, Egloff AM, Seethala $\mathrm{RR}$, et al. Intratumoral epidermal growth factor receptor antisense DNA therapy in head and neck cancer: first human application and potential antitumor mechanisms. J Clin Oncol 2009; 27(8): 123542.

[140] Cohen RB. Current challenges and clinical investigations of epidermal growth factor receptor (EGFR)- and ErbB family-targeted agents in the treatment of head and neck squamous cell carcinoma (HNSCC). Cancer Treat Rev 2014; 40(4): 567-77.

[141] Kang H, Kiess A, Chung CH. Emerging biomarkers in head and neck cancer in the era of genomics. Nat Rev Clin Oncol 2015; 12(1): 11-26.

[142] Misale S, Yaeger R, Hobor S, Scala E, Janakiraman M, Liska D, et al. Emergence of KRAS mutations and acquired resistance to antiEGFR therapy in colorectal cancer. Nature 2012; 486(7404): 532-6.

[143] Pylayeva-Gupta Y, Grabocka E, Bar-Sagi D. RAS oncogenes: weaving a tumorigenic web. Nat Rev Cancer 2011; 11(11): 761-74.

[144] Yoon HH, Tougeron D, Shi Q, Alberts SR, Mahoney MR, Nelson GD, et al. KRAS codon 12 and 13 mutations in relation to diseasefree survival in BRAF-wild-type stage III colon cancers from an adjuvant chemotherapy trial (N0147 alliance). Clin Cancer Res 2014; 20(11): 3033-43. 
[145] Heinemann V, Stintzing S, Kirchner T, Boeck S, Jung A. Clinical relevance of EGFR- and KRAS-status in colorectal cancer patients treated with monoclonal antibodies directed against the EGFR. Cancer Treat Rev 2009; 35(3): 262-71.

[146] Saki M, Toulany M, Rodemann HP. Acquired resistance to cetuximab is associated with the overexpression of Ras family members and the loss of radiosensitization in head and neck cancer cells. Radiother Oncol 2013; 108(3): 473-8.

[147] De Roock W, Claes B, Bernasconi D, De Schutter J, Biesmans B, Fountzilas G, et al. Effects of KRAS, BRAF, NRAS, and PIK3CA mutations on the efficacy of cetuximab plus chemotherapy in chemotherapy-refractory metastatic colorectal cancer: A retrospective consortium analysis. Lancet Oncol 2010; 11(8): 753-62.

[148] Boeckx C, Weyn C, Vanden Bempt I, Deschoolmeester V, Wouters A, Specenier P, et al. Mutation analysis of genes in the EGFR pathway in Head and Neck cancer patients: Implications for antiEGFR treatment response. BMC Res Notes 2014; 7: 337.

[149] Yonesaka K, Zejnullahu K, Lindeman N, Homes AJ, Jackman DM, Zhao F, et al. Autocrine production of amphiregulin predicts sensitivity to both gefitinib and cetuximab in EGFR wild-type cancers. Clin Cancer Res 2008; 14(21): 6963-73.

[150] Tinhofer I, Klinghammer K, Weichert W, Knodler M, Stenzinger A, Gauler T, et al. Expression of amphiregulin and EGFRvIII af- fect outcome of patients with squamous cell carcinoma of the head and neck receiving cetuximab-docetaxel treatment. Clin Cancer Res 2011; 17(15): 5197-204.

[151] Shames DS, Carbon J, Walter K, Jubb AM, Kozlowski C, Januario $\mathrm{T}$, et al. High heregulin expression is associated with activated HER3 and may define an actionable biomarker in patients with squamous cell carcinomas of the head and neck. PloS one. 2013; 8(2): e56765

[152] Troiani T, Martinelli E, Napolitano S, Vitagliano D, Ciuffreda LP, Costantino $\mathrm{S}$, et al. Increased TGF-alpha as a mechanism of acquired resistance to the anti-EGFR inhibitor cetuximab through EGFR-MET interaction and activation of MET signaling in colon cancer cells. Clin Cancer Res 2013; 19(24): 6751-65.

[153] Bedi A, Chang X, Noonan K, Pham V, Bedi R, Fertig EJ, et al. Inhibition of TGF-beta enhances the in vivo antitumor efficacy of EGF receptor-targeted therapy. Mol Cancer Ther 2012; 11(11): 2429-39

[154] Li C, Iida M, Dunn EF, Wheeler DL. Dasatinib blocks cetuximaband radiation-induced nuclear translocation of the epidermal growth factor receptor in head and neck squamous cell carcinoma. Radiother Oncol 2010; 97(2): 330-7. 